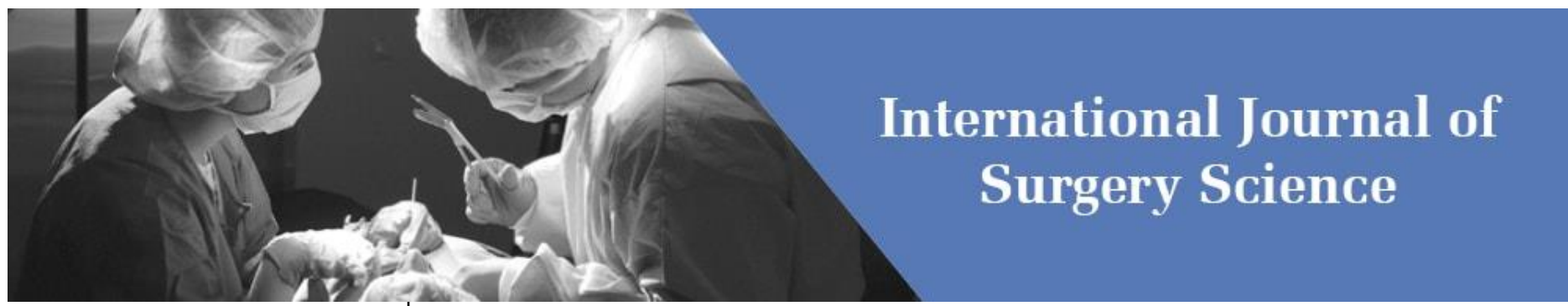

E-ISSN: 2616-3470

P-ISSN: 2616-3462

(C) Surgery Science

www.surgeryscience.com

2021; 5(1): 601-602

Received: 08-10-2020

Accepted: 19-11-2020

Dr. Prashanth Kumar K

Associate Professor, Department of Surgery, Srinivas Institute of

Medical Sciences, Mangalore,

Karnataka, India
Corresponding Author: Dr. Prashanth Kumar K Associate Professor, Department of Surgery, Srinivas Institute of Medical Sciences, Mangalore, Karnataka, India

\section{Study among injury victims in the department of surgery}

\section{Dr. Prashanth Kumar K}

DOI: https://doi.org/10.33545/surgery.2021.v5.i1g.641

\section{Abstract}

Accidents and injuries are very common in today's world. With the ever increasing dependence on the machinery, accidents are fairly common and regularly dealt in the clinics and in the Department of Surgery. As the first point of contact patients should be checked very carefully and very careful examination of the victim should be conducted. This will help us to diagnose and take appropriate timely action. This study is a demographic study to find the pattern of injuries that we meet in the Department of Surgery.

Keywords: Tertiary care, surgery, injury

\section{Introduction}

Accidents especially the RTA or the road traffic accidents are very common now a days ${ }^{[1]}$. Injury and deaths due to road traffic accidents (RTA) are a major public health problem in developing countries where more than $85 \%$ of all deaths and $90 \%$ of disability-adjusted life years were lost from road traffic injuries ${ }^{[2]}$.

The data for fatal accidents presented to the Parliament by the Ministry of Road Transport and Highways for year 2008 shows that 119,860 people perished in mishaps that year and the national and state highways accounted for nearly half of all road accidents ${ }^{[3]}$. Deaths due to road accidents in 2009 were reported to be 126,896 and in 2010 it increased to 133,938 which is about $5.5 \%$ over and above the previous year's deaths. Tamil Nadu, Andhra Pradesh, Maharashtra, Karnataka, and Rajasthan have accounted for $11.5 \%, 10.5 \%, 7.1 \%$, and $6.8 \%$, respectively, of total "Road Accident" deaths in the country ${ }^{[4]}$. The trend is alarming and is leading to a frightening situation day by day.

Many studies are necessary to identify and help the people by finding out the factors required for injury control so that the mortality, morbidity and disability can be reduced or rather prevented [5]. Accidents and injuries are very common in today's world. With the ever increasing dependence on the machinery, accidents are fairly common and regularly dealt in the clinics and in the Department of Surgery. As the first point of contact patients should be checked very carefully and very careful examination of the victim should be conducted. This will help us to diagnose and take appropriate timely action. This study is a demographic study to find the pattern of injuries that we meet in the Department of Surgery.

\section{Aims and Objectives}

To study the pattern among injury victims seeking service in the department of Surgery.

\section{Materials and Methods}

His study was done in the Department of Surgery, Srinivas Institute of Medical Sciences, Mangalore.

Seventy three cases that were admitted to the Department were studied in detail and an attempt has been made to report promptly.

\section{Exclusion criteria}

1. Only accident cases

2. Only above 18 years 


\section{Inclusion Criteria}

All the patients were 20-60 years. This was done to understand the patterns especially in the working group.

\section{Results}

Table 1: Age Distribution

\begin{tabular}{|c|c|c|}
\hline Number & Mean age & Std. Deviation \\
\hline 73 & 38.17 years & 11.41 years \\
\hline
\end{tabular}

Table 2: Sex Distribution

\begin{tabular}{|c|c|c|}
\hline Number & Male & Female \\
\hline 73 & 41 & 32 \\
\hline
\end{tabular}

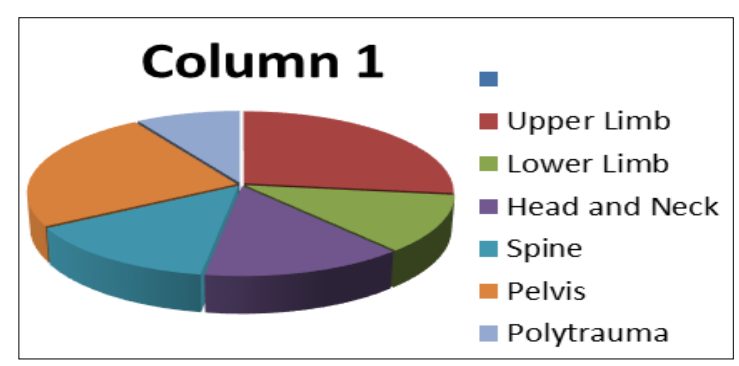

Graph 1: Parts Injured

Table 5: Common Modality of Treatment

\begin{tabular}{|c|c|}
\hline Parts Injured & Frequency \\
\hline Upper Limb & Amputation (1), Compartment syndrome (3) \\
\hline Lower Limb & Amputation (1), Compartment syndrome (4) \\
\hline Head and Neck & 11- Conservative \\
\hline Spine & 17- Conservative \\
\hline Pelvis & 09 Conservative \\
\hline Polytrauma & 33 (Poly care treatment) \\
\hline
\end{tabular}

Table 6: Disability

\begin{tabular}{|c|c|c|}
\hline Disability & Male & Female \\
\hline Temperory & 11 & 01 \\
\hline Permanent & 02 & 01 \\
\hline
\end{tabular}

Table 7: Outcomes

\begin{tabular}{|c|c|c|}
\hline Disability & Male & Female \\
\hline Dead & 01 & 02 \\
\hline Diabled & 11 & 01 \\
\hline
\end{tabular}

\section{Discussion}

Most countries have a multidisciplinary approach to traffic planning and road design. It is done by psychologists, engineers, doctors, sociologists, vehicle experts, etc., In India, road traffic is still a civil engineering issue. Lessons can be learnt from the eminent guidelines and good practices for good behavior on the roads practiced in developed countries where safety, orderliness, and discipline are ingrained in the citizens, come what may. Mere celebration of the annual Road Safety Week during the first week of January does not serve any purpose. Drivers should learn to show consideration and respect to co-vehicle drivers and pedestrians so that our roads become safer. But it looks a long way to go. India's Motor Vehicles Act lagging far behind the needs of a fast-motorizing society is painfully evident from its road safety record. In a country witnessing $10 \%$ annual growth in vehicles, and boasting a network of 3.3 million $\mathrm{km}$ of roads, the Bill for creation of a statutory National Road Safety and Traffic Management Board must be speeded up. Such an agency is vital to set standards for road design, inspect existing roads, and investigate accidents scientifically.

It should take a "zero tolerance" policy toward the most common transgressions-dangerous and reckless driving; disregard for traffic rules; jumping red lights; driving under the influence of liquor; failing to use seatbelts; and driving without a helmet-to bring about a visible change. But strict implementation of traffic rules and stringent punishments alone will not solve the persisting crisis. Change in the mind set of riders and drivers and road users realizing their responsibilities alone will bring about a change.

\section{Conclusion}

The pattern is fairly common if compared to the studies that have been conducted in other hospitals of the locality. Immediate actions and prompt treatment should be done in order to give a good life to the patients.

\section{References}

1. Ameratunga S, Hijar M, Norton R. Road-traffic injuries: Confronting disparities to address a global-health problem. [Last cited on 2011 June 27]; Lancet 2006;367:153340. Available

2. Nantulya VM, Reich MR. The neglected epidemic: Road traffic injuries in developing countries. [Last cited 2011 June 27]; BMJ 2002;324:1139-41.

3. Killer Roads. The Hindu. May 23. 2011. [Last cited 2011 Sept 17].

4. Accidental Deaths and Suicides in India National Crime Records Bureau. Ministry of Home Affairs. Government of India. [Last cited 2012 April 16], 2010.

5. Murray CJL, Lopez AD, Mather CD et al. The global burden of disease 2000 project. Geneva: (Revised) WHO 2001, pp36.

6. Australian burden of disease and injury study, 1998.

7. European International Union burden of disease and injury study, 2000. 